\title{
When Questions Are Answers: Using a Survey to Achieve Faculty Awareness of the Library's Electronic Resources
}

\author{
Sandra J. Weingart and Janet A. Anderson
}

The Utah State University (USU) Libraries spend approximately 11 percent of their materials budget on electronic resources. Because electronic resources occupy no shelf space and often are used from remote locations, it can be difficult to alert users to new resources at the library and to determine what sort of patron support is needed. This study investigated electronic database awareness and use by 856 USU administrators and teaching faculty. The responses revealed the need for greater publicity regarding new acquisitions, training opportunities, and methods of remote access. Unexpectedly, the survey itself, with its accompanying descriptions of databases and access methods, met many of the needs it identified.

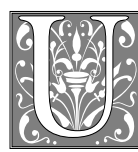

tah State University (USU) Libraries have been acquiring electronic resources for more than a decade. Today, locally mounted and Web-accessible electronic databases command approximately 11 percent of the institution's materials budget and provide access to information far beyond the limits of the libraries' print collections. But how does the university library make patrons aware of resources that occupy no traditional shelf space, and how does it determine what kinds of patron support are needed in the new electronic realm?

The USU libraries surveyed administrators and teaching faculty regarding their awareness and use of the libraries' electronic resources. Predictably, their re- sponses revealed the need for greater publicity on each new resource as it is acquired, training opportunities, and the mechanics of remote access to resources. Unexpectedly, the survey itself, with its accompanying descriptions of available electronic resources and guidelines for access, served to meet many of the needs it identified.

Results of the survey were made available via the libraries' home page and in hard copy. In all, fifty-five databases were publicized and more than eighty faculty questions were directly addressed. Although the libraries gained insight via the survey process, the greater benefit was the questionnaire's informational function for the faculty members.

Sandra J. Weingart is Science Reference Librarian in the Utah State University Libraries; e-mail: sanwei@cc.usu.edu. Janet A. Anderson is the Campus Services Librarian in the Utah State University Libraries; e-mail: janand@cc.usu.edu. 


\section{Literature Review}

A review of the literature showed that many surveys on the use of electronic resources involve point-of-use data collection through the log-on procedure, observation, or structured interview. ${ }^{1-3}$ Although these surveys included faculty members, none of them targeted faculty members specifically. A study at American University and the University of the District of Columbia used a mail survey but focused exclusively on third-year undergraduates. ${ }^{4}$ Those studies that have specifically targeted university faculty members show a persistent pattern of unawareness of the availability of particular resources and methods of accessfrom the early days of end-user searching through the Internet explosion.,

\section{Because the questionnaire was distributed to all administrators and teaching faculty, inferential statistics based on random sampling tech- niques would have been inappropri- ate tools for analysis.}

\section{Methods}

In January 1998, a two-part survey mailed to USU teaching faculty and administrators sought information on their knowledge and use of specific databases and electronic access to library-supplied information in general. Part one of the instrument listed the fifty-five databases then available electronically and used a checklist format to indicate for each database: awareness of its availability, faculty use, class/student use, and ease of use. Part two asked about general issues of electronic library access (e.g., Were you aware that some electronic databases can be accessed from your home or office? Have you ever accessed the university libraries' home page?). In addition, part two asked which, if any, library training sessions for electronic resources the respondents had participated in and how the respondents rated them. Questions about academic department, rank, and role (e.g., teaching, research, extension) supplied demographic data for further analysis of the findings. A final question solicited any other comments about electronic databases or the university libraries. On average, it took less than ten minutes to complete both parts of the survey. ${ }^{7}$

Along with the survey instrument, faculty members were sent an annotated list of the fifty-five databases covered by the survey. In addition to basic descriptive information, this list grouped the databases by access method for campus users: available via the libraries' online CD-ROM network, available only on workstations located in the reference departments, Webbased resources accessible through the USU domain, or accessible via the libraries' online catalog gateway. The list of databases was included to address the concern that faculty members might not recognize the names of the electronic resources they had used.

Surveys were sent to 881 individuals identified by the university's Office of Personnel Services as teaching faculty or administrators. Of these, twenty-five were retired, on sabbatical, or otherwise unavailable to respond. Using a modified Dillman methodology, a follow-up postcard was sent to the remaining 856 subjects and a second copy of the questionnaire was later mailed to on-campus teaching faculty members who did not respond to the initial mailing. ${ }^{8}$ A total of 426 individuals responded, for a return rate of 49.8 percent.

Because the questionnaire was distributed to all administrators and teaching faculty, inferential statistics based on random sampling techniques would have been inappropriate tools for analysis. Furthermore, the data collected suggest a strong response bias in favor of those with greater electronic experience. For these two reasons, only descriptive statistics were used to analyze the data generated by the survey and the results cannot be assumed to represent the administration and faculty as a whole.

\section{Results}

\section{Database Awareness}

The first question about each database simply asked whether the respondent was aware that the resource was available at USU in electronic format. As table 1 
When Questions Are Answers 129

\begin{tabular}{|c|c|c|}
\hline \multicolumn{3}{|c|}{$\begin{array}{c}\text { TABLE } 1 \\
\text { Awareness of Database Availability }\end{array}$} \\
\hline Database & $\begin{array}{c}\% \text { Unaware This } \\
\text { Database Was Available }\end{array}$ & $\begin{array}{c}\text { No. of } \\
\text { Responses }\end{array}$ \\
\hline ABI/Inform (business) & 55.8 & 353 \\
\hline Agricola (agriculture) & 37.9 & 351 \\
\hline America: History and Life & 59.6 & 344 \\
\hline American Business Disc & 66.7 & 339 \\
\hline Anthropological Literature & 60.9 & 340 \\
\hline Applied Science \& Technology Index & 48.1 & 343 \\
\hline Art Index & 59.5 & 341 \\
\hline Biological and Agricultural Index & 46.3 & 352 \\
\hline Biosis (biology) & 51.9 & 343 \\
\hline Business Periodicals Index & 52.4 & 347 \\
\hline City/County Databook & 61.3 & 341 \\
\hline Commsearch (communications) & 66.9 & 332 \\
\hline Compact Disclosure (business) & 67.4 & 337 \\
\hline Compendex Engineering Index & 65.6 & 334 \\
\hline Current Contents & 33.6 & 354 \\
\hline Deseret News & 40.8 & 341 \\
\hline Dissertation Abstracts & 24.0 & 363 \\
\hline EBSCOhost (journal articles) & 51.3 & 339 \\
\hline Education Index & 44.2 & 346 \\
\hline Environmental Periodicals Bibliography & 63.6 & 332 \\
\hline ERIC (education) & 34.6 & 353 \\
\hline Ethnic Newswatch & 67.9 & 333 \\
\hline Fish and Fisheries Worldwide & 65.1 & 332 \\
\hline FSTA Food Science \& Technology & 64.0 & 328 \\
\hline General Periodicals & 38.0 & 342 \\
\hline Georef (geology) & 65.3 & 331 \\
\hline Historical Abstracts & 59.7 & 335 \\
\hline Humanities Index & 52.1 & 338 \\
\hline Index to (US) Government Documents & 39.8 & 337 \\
\hline Index to Legal Periodicals \& Books & 59.6 & 329 \\
\hline Index to UN Documents and Publications & 63.7 & 328 \\
\hline Infotrac SearchBank (journal articles) & 55.4 & 334 \\
\hline MLA International Bibliography & 62.1 & 327 \\
\hline MathSci & 61.9 & 339 \\
\hline Medline (medicine) & 42.2 & 348 \\
\hline National Criminal Justice Service & 69.2 & 328 \\
\hline $\begin{array}{l}\text { NESE National Economic, Social, and } \\
\text { Environmental Data Bank }\end{array}$ & 69.9 & 332 \\
\hline New York Times Index & 44.2 & 342 \\
\hline NTDB National Trade Data Bank & 70.2 & 329 \\
\hline OnPoint (business) & 72.2 & 331 \\
\hline Psychlit (psychology) & 57.5 & 339 \\
\hline Reader's Guide to Periodical Literature & 38.3 & 350 \\
\hline Social Sciences Index & 41.5 & 347 \\
\hline Sociofile (sociology) & 63.4 & 347 \\
\hline Sport Database & 68.2 & 336 \\
\hline
\end{tabular}




\begin{tabular}{|lcc|}
\hline \multicolumn{3}{|c|}{$\begin{array}{c}\text { TABLE 1 (CONTINUED) } \\
\text { Awareness of Database Availability }\end{array}$} \\
\hline \hline Database & $\begin{array}{c}\text { \% Unaware This } \\
\text { Database Was Available }\end{array}$ & $\begin{array}{c}\text { No. of } \\
\text { Responses }\end{array}$ \\
\hline Statistical Abstract of the U.S. & 51.6 & 345 \\
Trademarks Registered & 68.7 & 332 \\
UMI ProQuest Direct (journal articles) & 69.9 & 336 \\
U.S. Patents (Class \& Bibliography) & 63.0 & 335 \\
U.S.A. Counties & 69.9 & 335 \\
Wall Street Journal & 41.0 & 344 \\
Water Resources Abstracts & 63.1 & 333 \\
Wildlife Worldwide & 65.5 & 336 \\
\hline
\end{tabular}

shows, Dissertation Abstracts received the highest rating, with 76 percent of respondents aware of its electronic availability. It was followed by Current Contents (66\%), ERIC (65\%), and Agricola, Wilson's Reader's Guide to Periodical Literature, and General Periodicals Index (each 62\%). Sixty percent of all respondents were aware of the electronic availability of Index to (US) Government Documents, whereas Wall Street Journal, Deseret News, and Wilson's Social Sciences Index were each known by 59 percent of respondents. The lowest rating was for the business database OnPoint, with only 28 percent of respondents aware of its availability.

Although these figures may seem high for awareness of electronic-format resources, it is important to remember that the total survey response rate was just under 50 percent and that a response bias favoring electronic database users is likely. The awareness figures were more useful when broken down by the respondents' academic departments. These data were made available to subject specialist librarians who could use them in their work with individual departments.

In a question designed to probe the validity of the survey instrument, respondents were asked: Did you have difficulty answering any of the questions about the databases because you did not know the name(s) of the database(s) you have used? Almost 27 percent answered yes. This response validated the concern that had prompted inclusion of the an- notated list of databases with the original survey mailing.

\section{Database Importance and Student Use}

Respondents who were aware of and use each database were asked to rate the importance of that database to their own work and to indicate whether they encourage or require their students to use it. Among these respondents, the resources rated as either "important" or "essential" to their own work by at least 50 percent of individuals included: Dissertation Abstracts (80\%), Current Contents (65\%), EBSCOhost (journal articles) (59\%), and ERIC (51\%). No individual database was recommended to students by more than 50 percent of those responding to each question. Less class use than faculty use also was suggested by the fact that response rates for this entire question category dropped dramatically-that is, among all the databases listed, the largest number of individuals (just 136) responded to this question for Dissertation Abstracts. Of these, 40 percent encourage or require student use of this electronic source. Three business-related resources had no recommended student use: American Business Disc ( $0 \%$ of 71 respondents), OnPoint ( $0 \%$ of 50 respondents), and Trademarks Registered ( $0 \%$ of 52 respondents).

\section{Ease of Use}

Response rates fell still lower when faculty members who use each electronic database were asked to rate ease of use. 
When Questions Are Answers 131

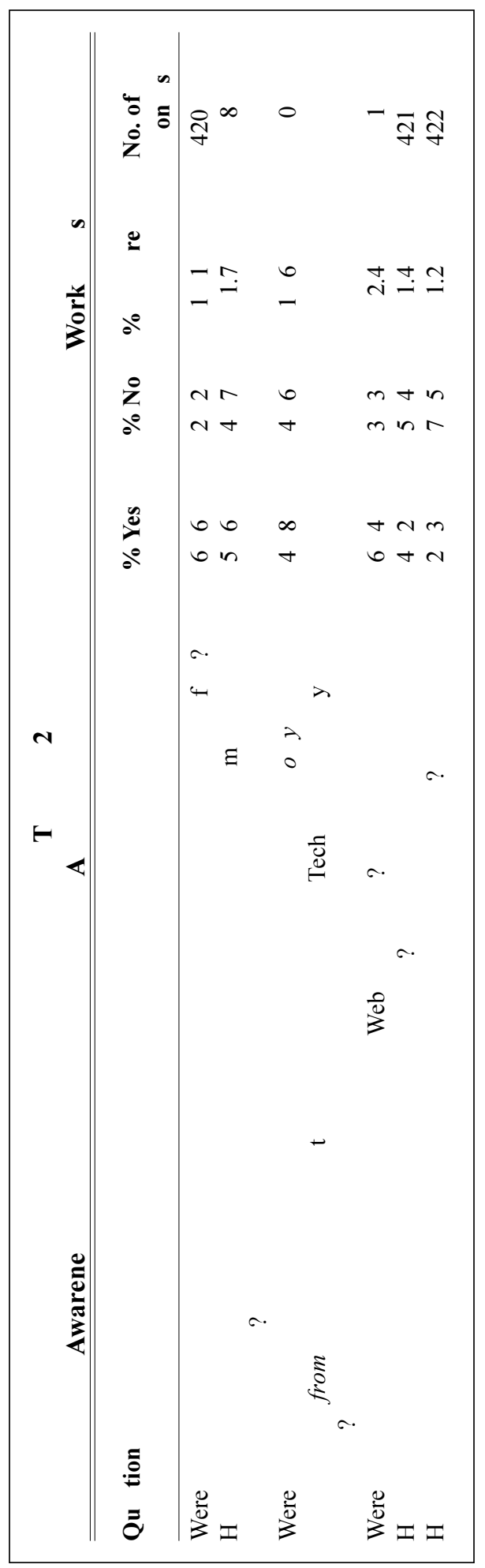

Current Contents elicited the greatest feedback, with ninety-eight people answering the question and 62 percent of these rating it "easy to use." At the low end of the responses, just three individuals answered for Medline, none of whom found it easy to use. The investigators hypothesized that faculty members may have been comfortable assigning an "importance for your own work" rating on the basis of database title alone, whether or not they actually used the electronic version of the resource. However, the low response rates on student use and ease of use may be truer indicators of actual faculty knowledge and use of the electronic formats.

\section{Remote Access to Library \\ Databases}

Although more than two-thirds of respondents $(68 \%)$ were aware that some of the libraries' electronic databases could be accessed from their home or office, only 54 percent had actually done so. And although almost two-thirds (64\%) were aware of the libraries' Web home page, less than half ( $48 \%$ ) had accessed it. Again, the relatively high awareness and use figures were tempered by the presumption of response bias in favor of faculty with greater electronic skills. Forty-five percent of respondents were aware that (due to licensing agreements) some of the libraries' electronic databases could be accessed only from terminals located in the two library buildings (see table 2).

\section{Database Training}

Ninety-six respondents (23\%) had attended library-provided instruction for one or more electronic databases. Of these, 80 percent had attended just one instruction session, 14 percent had attended two, and 6 percent had attended three or four. The most commonly attended workshop was training for either EBSCOdoc or EBSCOhost resources (one-third of attendees). Twenty-seven percent of respondents had attended training on Lexis/Nexis, and 13 percent had received library instruction in the use of Agricola. 
When asked to rate the effectiveness of workshop training (ninety-nine workshop sessions were evaluated), 41 percent rated the instruction they received "better than adequate," 50 percent rated it "adequate," and 10 percent rated it "inadequate." These ratings were analyzed by workshop rated, and the data were provided to the librarian-instructors. However, low response rates rendered this information less useful than the evaluation process that is conducted in each workshop on a regular basis.

\section{Respondent Comments and Questions}

Comments and questions on any libraryrelated topic were solicited at the end of the survey. Most common were requests for databases the libraries did not then offer in electronic format. Twenty-two respondents $(5 \%)$ requested a total of nineteen databases. Twelve people (3\%) expressed the wish that all databases were available electronically, and twelve (3\%) indicated a need for more information, documentation, or guidance on accessing electronic resources remotely. In all, twenty-seven people (6\%) expressed their compliments or thanks for various library services (e.g., "We're making good progress," "I'm so grateful to have access from my office," "The libraries' Web site is exciting!," "Library personnel are very helpful"). Many individuals expressed specific concerns or questions, such as: "Access is too slow!" "I can't figure out how to print from Agricola and Current Contents," "I can never access PsycLit from my office."

\section{The main finding from the survey data was that the university libraries need to work harder to publicize the available electronic resources, how to access them, and what each database has to offer.}

Several people requested services that were already in place (e.g., "Would be interested in services that allow me to download entire journal articles"). Some were simply unclear in their meanings: "When I need them, I want them there" and "Please-USU Libraries home page."

The first clue that the survey was as useful to those being surveyed as it was to those administering the survey was the early response: "If this is your way of hinting that I might want to make myself more aware of the libraries' holdings, I get the point." Eleven respondents expressed appreciation for the materials that were distributed with the survey: "Survey was very informative" and "Thanks for the list of databases!"

\section{Discussion}

The survey provided the libraries with some concrete and "actionable" information on how faculty members use the libraries' electronic resources. For example, when analyzed by academic department, survey data allowed librarians to address needs for information and access support within particular disciplines. The main finding from the survey data was that the university libraries need to work harder to publicize the available electronic resources, how to access them, and what each database has to offer.

The investigators did not anticipate in advance that the survey and the accompanying documentation of available databases and access methods would go a long way toward meeting the needs the survey itself identified. What better publicity for the databases than to distribute an annotated list to every individual faculty member? Both the accompanying lists and the survey instrument served to publicize available electronic resources. The survey's request for comments brought out many questions that previously had gone unasked and therefore unanswered.

Tables of results were shared with library faculty members, and a summary of key findings was posted on the libraries' home page. In addition to the summary of findings, the home page report addressed every question submitted by survey respondents. Questions were grouped by topics (e.g., CD-ROMs, li- 
When Questions Are Answers 133

\begin{tabular}{c} 
FIGURE 1 \\
Sample Page "University Libraries' Database Survey: \\
Response to Faculty Comments" \\
\hline \hline
\end{tabular}

\section{CD-ROMS}

- Leaving CDs on the tower for over a year is poor service, especially when updates arrive quarterly.

- It is very hard to get into the CD-ROMs from home.

- For databases located only on terminals in Merrill Library: This is a drag!

- Need to have user's manuals available nearby where the databases are used.

- The CD-ROMs are clunky and slow to use.

- Consider putting all databases on the same frontend (i.e., web page) using a Winspirs-like program. Databases are accessed by a hodgepodge of routines that is inefficient (mapping local drives, telnet to OPAC, etc.). It's a big mess!

\section{The Library responds:}

CD-ROM updates are mounted as they are received. During the past year we have had some difficulties with a few of our subscriptions. After these were ironed out and we began receiving the updates again, we made them available. Several are only updated once a year.

With regard to connection to the CD-ROM databases from home, the issue is licensing and user authentication. USU libraries purchase site licenses for these databases and must restrict access to users within the USU community. Patrons are currently unable to access the CD-ROM network from off campus. We are aware of the difficulties associated with this and are looking for alternatives that may allow password-controlled access to the libraries' databases from off-campus locations.

Some databases are only available in Merrill Library because a multi-user site license is simply beyond the range of our budget resources.

Search guides for many of our databases are available on literature racks in the Reference Areas of both libraries. More in-depth guides can be found at the reference desks. And it is always appropriate to ask a reference librarian for assistance. The Merrill reference desk can be reached at 797-2678; Sci-Tech reference desk at 7972917.

As for the clunkiness of the interface: well, we're trying. We have a couple of sticking points. One is that there are so many search interfaces out there. It's impossible to find one that will work for every database we have, especially as regards the online catalog and the journal indexes. The databases are built differently, and what works well with one is not appropriate with the other. In addition, some of the software just can't be made to work together. We are also trying to satisfy a diverse clientele. If a search interface is user-friendly and intuitive, it will sacrifice the sophisticated capabilities that experienced searchers want. In many cases, we don't choose the interface. We simply use what comes with the databases, as it is sometimes the only thing that will work. We are always looking for a good middle ground. 
brary staff and customer service, connectivity, etc.) and answered in a "The library responds ..." format (see figure 1). ${ }^{9}$ The availability of this information was announced in a hard-copy flyer sent to every faculty member. Faculty response was very positive. In fact, it was clear that the survey process itself had met many of the faculty's information needs.

\section{Epilogue}

Since this survey was completed, USU libraries have continued to acquire new databases, bringing the total to seventyfive as of August 1999. In addition, methods of remote access have been streamlined. With the migration to a Web-based environment, it has become much easier to offer one-stop shopping for the libraries' electronic resources. Rather than four separate access points-the Library Gateway, CD-ROM network, World Wide Web subscriptions, and stand-alone CDsUSU libraries now offer access to all but a few of the seventy-five electronic databases from the Library Gateway. ${ }^{10}$

\section{Notes}

1. Peter Hyland and Lynne Wright, "Profile of Patrons and Their Use of CD-ROM Databases in an Academic Library," Australian Library Journal 44 (May 1995): 90-100.

2. Amy Tracy Wells, "Analysis of User Need with CD-ROM Databases: A Case Study Based on Work Sampling at One University Library," ERIC Document Number ED 368361 (Nov. 1992).

3. Alice Omaji, "Non-Use of CD-ROM Databases in an Academic Environment," CD-ROM Librarian 14 (Oct. 1994): 45-46.

4. Ingrid Hsieh-Yee, "Student Use of Online Catalogs and Other Information Channels," College E Research Libraries 57 (Mar. 1996): 161-75.

5. Katharine E. Clark and Joni Gomez, "Faculty Use of Databases at Texas A\&M University," $R Q 30$ (winter 1990): 241-48.

6. Janet F. Laribee and Carl L. Lorber, “Electronic Resources: Level of Awareness and Usage in a University Library," CD-ROM Professional 7 (Nov./Dec. 1994): 137-38, 140-42, 144.

7. Copies of the survey instrument may be requested from the authors.

8. Don A. Dillman, Mail and Telephone Surveys: The Total Design Method (New York: John Wiley \& Sons, 1978).

9. Copies of the "Response to Faculty Comments" document may be requested from the authors.

10. Library Gateway is located at http://libcat.usu.edu. 